\title{
DOENÇAS DO TRABALHO exclusão, segregação e relações de gênero
}

Celso Amorim Salim

\begin{abstract}
Resumo: A partir do quadro geral dos acidentes e doenças do trabalho, analisam-se a evolução e as características sociais e demográficas das LER/Dort na RMBH nos anos 90 do século XX. Para isso, retém-se a dinâmica do mercado de trabalho e os mecanismos de exclusão e segregação que lhe são subjacentes, identificando, ao final, da perspectiva de ocupação e gênero, situações específicas e conseqüências diferenciadas à saúde dos trabalhadores.

Palavras-chave: doenças do trabalho; LER/Dort; segregação ocupacional por gênero.
\end{abstract}

Abstract: Using as its basis a general overview of work-related accidents and illnesses, this article analyzes the evolution and social and demographic characteristics of the LER/Dort in the RMBH in the 1990s. To this end, consideration is given to the dynamics of the labor market and the underlying mechanisms of exclusion and segregation, ultimately identifying specific situations and unique consequences affecting worker health according to occupational type.

Key words: labor-related illnesses; LER/Dort; occupational and work-type segregation.

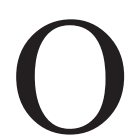
crescimento das LER/Dort entre as doenças do trabalho vem sendo objeto de estudos tópicos diversos. Todavia, mesmo pela justificativa da multidisciplinaridade, a maioria das análises existentes concentra-se basicamente em aspectos parciais ou específicos da etiologia da doença, reduzindo tanto abordagens mais amplas - inclusive em nível conceitual - quanto o seu entendimento das rápidas mutações por que vem passando o mundo do trabalho. ${ }^{1}$

Abstraindo-nos de uma análise sobre as suas manifestações clínicas, pontua-se, no entanto, que, embora não sejam doenças recentes, as LER/Dort vêm, sem dúvida, assumindo um caráter epidêmico, sendo algumas de suas patologias crônicas e recidivas, ou seja, de terapia difícil, porque se renovam precocemente quando da simples retomada dos movimentos repetitivos, gerando uma incapacidade para a vida que não se resume apenas ao ambiente de trabalho.

Mesmo que vários fatores intervenham na formação das LER/Dort, sua determinação, em última instância, perpassa pela estrutura social, relacionando-se, sobretudo, com as mudanças em curso na organização do trabalho e secundariamente com as inovações tecnológicas peculiares à reestruturação produtiva. E mais: sob as relações de gênero, o seu acometimento quantitativo maior expressa-se, sobretudo, através da mulher trabalhadora, fato diretamente relacionado não a uma "suposta" propensão biológica, mas, como veremos, ao papel e à forma de inserção da mulher nas divisões social e sexual do trabalho. Por outro lado, a expansão dos casos de LER/Dort vem acarretando, pelos números ascendentes de benefícios pleiteados ou concedidos, fortes impactos no sistema de previdência pública e, por conseguinte, na distribuição do ônus para o conjunto da sociedade.

Buscando a compreensão das determinações das LER/ Dort no contexto da relação saúde-doença como processo social resultante do desgaste do trabalho (Laurell e Noriega, 1989), tomamos como cenário de nosso objeto de estudo as mudanças macros ocorridas no mercado de trabalho da Região Metropolitana de Belo Horizonte RMBH nos anos 90. Vale dizer que, no contexto da RMBH, a análise da evolução e das características sociais e demográficas das LER/Dort, assim como das relações de exclusão social e segregação ocupacional que lhe são subjacentes, será diretamente remetida às novas condições de organização do trabalho. 
Nesse sentido, pela perspectiva sociológica e com base em diferentes fontes de dados, a investigação direciona-se, em especial, para a análise das LER/Dort consoante quatro aspectos: primeiro, o contexto da evolução das ocorrências de acidentes e doenças do trabalho; segundo, a dinâmica do mercado de trabalho em geral e na RMBH em particular, enfatizando-se os influxos do emprego e desemprego e o Setor Serviços; terceiro, o quadro das mudanças sociodemográficas em curso; quarto, a incorporação da categoria gênero, identificando situações específicas assim como as conseqüências diferenciadas à saúde de homens e mulheres. Especificamente, dados epidemiológicos do Nusat $^{2}$ - Núcleo de Referência em Doenças Ocupacionais da Previdência Social são arrolados na perspectiva, através da análise comparativa, de compreender tanto a evolução do perfil das LER/Dort - isto é, segundo as variáveis sexo, idade, escolaridade, ocupação e renda - como, em especial, os agravos resultantes da situação ocupacional dos trabalhadores e trabalhadoras distribuídos segundo os ramos de atividade econômica e tempo nas funções inerentes às ocupações no mercado de trabalho da RMBH.

Importante registrar que os dados do Nusat, amplos e basicamente remetidos aos casos diagnosticados de doenças do trabalho, a par de facultarem a perspectiva analítica proposta, constituem, no geral, exemplo concreto de como podemos redirecionar ações conjuntas para a melhoria das estatísticas e indicadores sobre a saúde do trabalhador. Isso, sem dúvida, não desconsiderando a potencialidade dos trabalhadores como rica fonte de informações para o delineamento de perfis apropriados da trajetória recente das doenças do trabalho na $\mathrm{RMBH}$, mormente em seu mercado formal de trabalho. Afinal, desde a extinção do Nusat, e perante a não-realização de pesquisas amostrais apropriadas, a RMBH necessita de informações mais acuradas sobre a questão, apesar de sua inquestionável emergência.

\section{APORTES TEÓRICOS E METODOLÓGICOS}

Diante da complexidade do tema "reestruturação produtiva" - no caso, englobando novo padrão tecnológico, mudanças organizacionais, novos valores e práticas de gestão, novo perfil do trabalhador, etc. - e suas imbricações com o processo de saúde do trabalhador em estruturas capitalistas, serão apontados abaixo apenas alguns elementos teóricos atinentes ao tema "organização do trabalho e determinação social do processo saúde-doença”, com o objetivo de tão-somente destacar o fio condutor do presente estudo.

\section{Mudanças na Organização Social do Trabalho}

As novas formas de organização do trabalho associadas ao processo de reestruturação produtiva configuramse como resposta à crise de realização capitalista ocorrida no modelo anterior, caracterizado pela generalização dos princípios tayloristas-fordistas.

Diante do novo modelo econômico surgido nos anos 80 nos países avançados, destacam-se, consoante Pires (1998:45-46) "a grande importância do setor eletrônico; a intensa aplicação da tecnologia digital de base microeletrônica na estrutura industrial; e os progressos nos setores da química fina, dos novos materiais, da biotecnologia e da engenharia genética, beneficiados com os progressos da informática". E mais: contrapondo-se à rigidez anterior, as mudanças suportam-se "no complexo eletrônico, e a automação integrada flexível é uma de suas características mais importantes".

No entanto, as mudanças no processo de trabalho, sobretudo em formações capitalistas periféricas, caracterizaram-se pela justaposição de formas tradicionais e inovadoras, ou seja, através do que se poderia chamar de "modernização conservadora" com fortes resquícios da segunda revolução industrial e tecnológica. Daí a manutenção e/ou revitalização dos princípios tayloristasfordistas, pela desqualificação e controle autoritário da força de trabalho (Braverman, 1977).

$\mathrm{Na}$ realidade, a par dessas inovações tecnológicas, advieram mudanças organizacionais que causaram impactos imediatos em todo o processo de trabalho. Exemplarmente, ante a verticalização das empresas, promove-se a terceirização quando várias atividades passaram a ser externalizadas, possibilitando maiores trocas intersetoriais, a diversificação e ampliação do Setor Serviços, o enxugamento do quadro de pessoal das grandes empresas, etc. Ainda na direção do aprofundamento da divisão do trabalho social, novos segmentos, refletindo a necessidade de rever custos e reduzir pessoal, indicam uma presumível terceirização da terceirização - a chamada quarteirização - que implica o concurso de novas empresas para gerenciar atividades que foram terceirizadas, ou seja, "um maior enxugamento dos setores próprios da empresa que gerenciam o trabalho das empresas terceirizadas" (Pires, 1998:47). 
É claro que esses processos não se restringem ao universo fabril, avançando sobre o Setor Serviços e alterando suas clássicas funções, relações e condições de trabalho (Offe,1989). Todavia, mesmo ampliando a sua participação na estrutura ocupacional, o Setor Serviços, diante dos impactos das novas tecnologias, não tem ampliado suficientemente os postos de trabalho a fim de absorver o desemprego gerado em outros setores (Pochmann, 1999).

Ao lado da redução do emprego direto e da maior subcontratação de trabalhadores, as novas relações de produção e formas de gestão se traduzem em alterações tanto na organização da produção - "just in time, layout, logística, redução do tamanho da planta, terceirização e parcerias com fornecedores" - como na organização interna do trabalho, "com redução de hierarquia, trabalho em ilhas, trabalho mais qualificado no núcleo estável e pouco qualificado nas atividades secundárias" (Pochmann, 1999:35-36). Paralelamente, além do declínio do trabalho na produção e das mudanças no mercado e nas relações de trabalho, entre outras, destacando-se a desregulamentação, a flexibilização e o enfraquecimento do poder sindical (Toledo, 1997), vêm ocorrendo modificações profundas na natureza, significado e conteúdo do trabalho.

Mais especificamente, no processo de terceirização, várias conseqüências podem ser apontadas. Porém, lembrando os seus possíveis impactos na saúde do trabalhador, destacamos as seguintes: a) segmentação e diferenciação dos trabalhadores quanto às condições de trabalho por exemplo, em relação ao gradiente de afastamento desde o centro da cadeia produtiva até as diversas unidades periféricas; b) por um lado, pulverização da base e enfraquecimento do poder sindical; por outro, flexibilização dos direitos trabalhistas; c) redução dos empregos diretos e indiretos ao longo da cadeia produtiva; d) intensificação do ritmo de trabalho e aumento da pressão no ambiente de trabalho.

No Brasil, particularmente nas regiões metropolitanas, tais processos se suportaram na heterogeneidade do mercado de trabalho, caracterizado pela queda do emprego no setor formal e expressiva elevação da ocupação no setor informal, que, por sua vez, inclui os "sem-carteira assinada" e os trabalhadores "por conta própria". Esses, somados aos desempregados, indicariam não apenas o grau de precariedade do mercado de trabalho como, sem dúvi$\mathrm{da}$, as bases em que se assenta o próprio processo de precarização das condições de trabalho, atribuídos por exemplo, à reprodução de baixos níveis salariais, à nãocobertura da seguridade social e à falta de assistência médica. Processo, hoje, que não pode ser exclusivamente imputado ao setor informal do mercado de trabalho, pois, em direções e graus variados, também tem avançado sobre o contingente de trabalhadores registrados.

\section{Determinação Social das LER/Dort}

Consoante Laurell e Noriega (1989), pressupõe-se que a partir da determinação histórica e social dos processos de saúde e doença se torna possível analisar os impactos dos ambientes de trabalho (condições materiais) e das formas de organização do trabalho (condições sociais historicamente determinadas) na vida dos trabalhadores.

Por conseguinte, essenciais não são as características estáticas do posto de trabalho, mas os "movimentos dinâmicos dos elementos do processo de trabalho". Enfim, as causas como expressão particular da forma específica de se produzir e, portanto, de trabalhar, ou melhor, de inserção na estrutura social via divisão social do trabalho, instância que torna possível a análise das formas de desgaste das cargas de trabalho e sua relação com as doenças ocupacionais. Isso porque "a construção teórica da relação entre processo de valorização, processo de trabalho, cargas de trabalho e processo de desgaste confere certa capacidade de predição com relação ao que caracteriza o padrão de desgaste de um determinado grupo de trabalhadores" (Laurell e Noriega, 1989:110).

No caso das LER/Dort, a retenção do caráter social do processo saúde-doença e de sua determinação possibilita, diante de suas diversas patologias, entender suas manifestações de forma concreta, isto é, em seus aspectos multifáticos remetidos às condições organizacionais patogênicas. Evita-se, assim, a centralidade da análise das LER/Dort nos "fatores" - pautada, por exemplo, em explicações multicausais ou multifatoriais - que, via de regra, reduzem, através do paradigma médico dominante, as LER à condição de fenômeno biológico e individual, cujo diagnóstico clínico, aliás, problemático, tem sido objeto de grandes controvérsias. Contrapondo-se às abordagens meramente aditivas, Lima (1997:249) aponta: “enquanto as dimensões organizacionais, estruturantes essenciais da situação de trabalho, forem consideradas apenas como mais um 'fator' dentre outros, como acontece com as abordagens tradicionais, as LER permanecerão um problema incompreensível e as tentativas de sua prevenção, inefetivas". 


\section{EMPREGO E PRECARIZAÇÃO DIANTE DE ACIDENTES E DOENÇAS DO TRABALHO}

\section{Quadro Geral}

No último quartel do século XX, o Brasil apresentou um quadro bastante adverso em relação tanto à expansão do mercado de trabalho quanto à melhoria das condições laborais daqueles que, a expensas do número crescente de excluídos, ali se encontravam engajados.

Em um contexto duplamente caracterizado pela prolongada estagnação econômica das décadas de 80 e $90-$ também conhecidas como "décadas perdidas" - e pela abertura unilateral de mercado, observaram-se, além da inevitável "exportação de empregos" para outros países, mudanças internas de monta na organização e nos processos de trabalho, seja através da adoção de novas tecnologias, seja em nome da competitividade, por meio da racionalização da produção, sobretudo por mudanças organizacionais voltadas à redução de custos. Mais que a primeira, basicamente atrelada à inovação, a última foi tida como a principal responsável tanto pela elevação da taxa de desemprego como pela maior precarização das condições de trabalho em geral, por exemplo, por subcontratações ou terceirização.

Particularmente, os anos 90 foram piores em indicadores do mercado de trabalho. O índice de desemprego para aquela década foi, em média, de $6,1 \%$. Vale dizer, por um lado, que a cada ano da década de 90 , cerca de 570 mil trabalhadores perderam seus postos, conforme atestam os dados da Fundação IBGE. Por outro, segundo a PNAD, também realizada pelo IBGE, a mera elevação do emprego informal e da subcontratação no total de ocupados de $41,5 \%$ para $49,4 \%$, entre 1990 e 1997 , resultou no incremento de 6,4 milhões de trabalhadores ${ }^{3}$ sem qualquer proteção legal, ou seja, simultaneamente sob os impactos da exclusão de direitos e da precarização no ambiente de trabalho. E, como vimos, o Setor Serviços, mesmo ampliando a sua participação relativa na estrutura geral de empregos, diante de sua nova inserção econômica, não tem sido capaz de se contrapor ao desemprego ascendente, especialmente nas regiões metropolitanas.

No entanto, como sorte de contradição, foi nesse contexto que emergiram propostas de flexibilização do mercado de trabalho voltadas à redução tanto da jornada de trabalho, por banco de horas, como de direitos trabalhistas, por regimes jurídicos diferenciados, em que, especialmente para a pequena e média empresa, aventou-se inclusive a reversão de direitos já consignados. ${ }^{4}$ Isso sem desconsiderar que, paralelamente às deficiências na cobertura da fiscalização, foi - e continua sendo - inexpressivo o aumento de cláusulas sobre saúde e condições de trabalho nos Acordos Coletivos de Trabalho (Salim, 2001).

Em outras palavras, um quadro caracterizado por dois aspectos: por um lado, pela retração do mercado de trabalho; por outro, pelo avanço na deteriorização das condições laborais daqueles cujos postos ou ocupações se encontram em níveis diferenciados de formalidade das relações contratuais ou empregatícias. Situação, enfim, que tem trazido importantes reflexos nas variações e tendências dos acidentes do trabalho no país.

Entrementes, paralelamente à redefinição do Setor Serviços, ocorreram a queda dos assalariados na participação total da população economicamente ativa (PEA) e o incremento de todo o mercado informal de trabalho. O último, hoje, em muitos casos, com participação majoritária no mercado de trabalho e indícios de saturação na absorção de trabalhadores excluídos do setor formal, traduz-se, inexoravelmente, no maior número de trabalhadores à margem dos direitos sociais, como o acesso à previdência social e ao bem-estar no ambiente de trabalho, através do inalienável direito a saúde e segurança.

De forma reflexa, as estatísticas disponíveis indicaram, no final da década, uma nova tendência quanto ao quadro acidentário no país. Em 1999, pela primeira vez na história laboral do país, tivemos uma maior ocorrência de acidentes do trabalho no Setor Serviços. Segundo a Previdência Social, enquanto, entre 1997 e 1999, a participação desse setor subiu de $38,7 \%$ para $44,6 \%$, inversamente, a participação da Indústria caiu de 49,2\% para 44,2\%. ${ }^{5}$ Participação, inclusive, que se estende ao número de casos fatais, ou seja, às mortes decorrentes de acidentes do trabalho. Nesse particular, destacaram-se os grupos ocupacionais dos ramos de atividade Serviços e Comércio e Transporte e Comunicação, como destacou Waldvogel (2002). Aliás, a autora, em sua criteriosa análise, aponta a emergência de se considerarem os fatores exógenos ao ambiente de trabalho na detecção dos riscos intrínsecos dos acidentes do trabalho, especialmente nos casos em que os trabalhadores têm ampliado para o espaço público o local de trabalho, incorporando, neste caso, novos riscos às suas atividades laborais como, por exemplo, a violência do cotidiano, expressa, principalmente, nas taxas de homicídios, acidentes com veículos a motor, atropelamentos, etc. Eventos, infelizmente, muitas vezes à margem das estatísticas disponíveis sobre acidentes do trabalho. 
Razão, dentre outras, que impõe a não-desconsideração dos limites intrínsecos nas fontes de dados que interferem na qualidade das informações sobre o quadro de saúdedoença relacionado ao trabalho no Brasil (Salim, 1999). Isso porque, basicamente referidas à infortunística dos trabalhadores do setor formal urbano, as estatísticas oficiais resumem-se, sobretudo, aos indicadores mínimos e de cunho burocrático - uma vez que, no geral, o são para fins dos benefícios previdenciários dos trabalhadores registrados - dos efeitos do trabalho no quadro de acidentes típicos e de trajeto, incapacidades permanentes ou temporárias e mortes provocadas. Exatamente por isso são tidas como subestimadas, retratando apenas parcialmente a realidade acidentária do mercado de trabalho brasileiro.

Apesar disso, e ainda consoante dados da Previdência Social, mesmo com a queda do número total de acidentes do trabalho, incluindo aí o número absoluto de mortes, a proporção de acidentes graves e o número de mortes por acidentes registrados, cresceram no tempo, ou seja, seu grau de letalidade, especialmente até 1995, quando, à exceção de 1992, os índices foram ascendentes, voltando, no entanto, a recrudescer ao final da década de 90 .

Por outro lado, inversamente à queda absoluta dos acidentes de trabalho, ocorreu um forte crescimento das doenças relacionadas ao trabalho durante toda a década de 90 , valendo aqui assinalar as mais diretamente relacionadas às recentes mudanças na organização do trabalho, em que as LER/Dort afiguraram-se como caso emblemático.

De fato, como reflexo de novos riscos nos processos produtivos e nos ambientes de trabalho, houve uma forte elevação nos coeficientes de doenças profissionais nos anos $90 .{ }^{6} \mathrm{E}$ isso foi mais do que sintomático, na medida em que, afora outros motivos, esses coeficientes retrataram um momento - mais precisamente, o final da década de 90 - em que se ergueu, por parte do Ministério da Previdência e Assistência Social, um verdadeiro "biombo institucional" para dificultar o diagnóstico e o reconhecimento de tais doenças, especialmente das LER/Dort, e, por conseguinte, a consignação de direitos aos lesionados (Araújo, 2001). ${ }^{7}$ Por outro lado, ainda que eloqüentes, são coeficientes que não podem ser dissociados de problemas inerentes às conhecidas dificuldades de melhoria nos sistemas de notificação das doenças do trabalho em diferentes contextos institucionais, ou seja, são calcados em inequívoca subenumeração de casos de doenças do trabalho.

Pesquisa recente do Instituto Nacional de Prevenção das LER/Dort (Prevler), realizada pelo Datafolha, com financiamento do Ministério da Saúde, ${ }^{8}$ mostrou que, apenas na cidade de São Paulo, cerca de 310 mil trabalhadores sofrem de LER/Dort, ou seja, casos realmente diagnosticados. Isso equivale a $4 \%$ de todos os paulistanos acima de 16 anos de idade e $6 \%$ de todos os trabalhadores da cidade. Número, aliás, muito acima dos 19 mil casos dessas doenças contabilizados pelo Ministério da Previdência no ano de $2000 .{ }^{9}$ E mais: a pesquisa da Prevler aponta que esse número pode estar aquém da realidade, uma vez que 4,7 milhões de trabalhadores relataram algum sintoma decorrente dessas doenças e 508 mil trabalhadores encontravam-se ocupados em situações de risco, fato que pode transformálos em novos portadores de LER/Dort - doença, registre-se, que tem sido a responsável pelo maior número de afastamentos do trabalho em São Paulo.

\section{Situação e Tendências em Belo Horizonte}

As variações nos indicadores demográficos, de emprego e condições de saúde e segurança no trabalho na RMBH, apontam para uma tendência divergente ou, até, paradoxal.

Segundo o IBGE, enquanto o crescimento populacional decresceu de $2,5 \%$ para $1,9 \%$, respectivamente nos períodos de 1980-91 e 1991-96, a PEA cresceu, em média, 0,4\% ao ano no último período, passando de um contingente de 1.610,4 mil para 1.642,5 mil pessoas. ${ }^{10}$ Já a taxa de desemprego, refletindo a crise econômica que se estende desde os anos 80, em elevação progressiva, saltou de 4,1\%, em 1991, para 4,6\%, em 1996. ${ }^{11}$

Quadro, na verdade, fortemente caracterizado pelo movimento geral de "desassalariamento" e precarização do trabalho vis-à-vis ao crescimento de ocupações no mercado informal de trabalho, que sozinho respondeu por quase $50 \%$ de todas as ocupações no âmbito da $\mathrm{RMBH}$, segundo a PME.

Considerando a distribuição das pessoas que trabalharam segundo a posição na ocupação, verificou-se, ainda segundo o IBGE, um decréscimo absoluto e relativo no número de trabalhadores com carteira assinada, que passou de um contingente de 804,8 mil, em 1991, para 736,2 mil, em 1996, implicando uma taxa média anual negativa de 1,8\%. Em contrapartida, o número de ocupados sem carteira assinada - isto é, não-registrados - , crescendo a uma média de 3,9\% ao ano, saltou, no período, de 339,5 mil para 394,3 mil trabalhadores. Já a categoria dos trabalhadores "por conta própria" aumentou de 328,7 mil para 353,8 mil indivíduos, ou seja, 1,4\% ao ano. Em relação 
ao total da população ocupada na $\mathrm{RMBH}$, as duas últimas categorias representaram $42,4 \%$ e $47,7 \%$, respectivamente, nos anos 1991 e 1996.

Apesar do caráter parcial das estatísticas disponíveis sobre os agravos à saúde do trabalhador - mesmo em relação à cobertura do setor formal (Salim, 2000b) -, observou-se, no âmbito da RMBH, o contraditio relacionado à diminuição dos acidentes de trabalho, por um lado, e elevação dos índices de doenças ocupacionais, por outro. Tendência que, guardadas as devidas proporções, foi a mesma observada para o conjunto do Estado de Minas Gerais. Tal tendência reverteu-se a partir de 1998, quando então se observou uma brusca e inusitada queda nos registros de doenças do trabalho em relação ao conjunto de acidentes do trabalho registrados nas publicações da Previdência Social. Situação basicamente explicada pela imposição de novas condições para os diagnósticos clínicos, apesar da manutenção das condições produtoras das doenças e tibieza das ações preventivas na área no período (Gráfico 1). ${ }^{12}$

Entre 1991 e 1996, Minas Gerais registrou, cumulativamente, 21.158 casos dessas doenças. Apenas em 1996 foram 8.010 casos, o que representou um crescimento de $55,6 \%$ em relação ao ano anterior. Desses, um total de 4.587 registros, correspondendo a $57,3 \%$ do total para o Estado, referia-se aos municípios mais industrializados da RMBH: Belo Horizonte (3.063), Contagem (1.063) e Betim (461). ${ }^{13}$

\section{GRÁFICO 1}

Evolução dos Acidentes Típicos e Doenças do Trabalho Minas Gerais - 1990-96

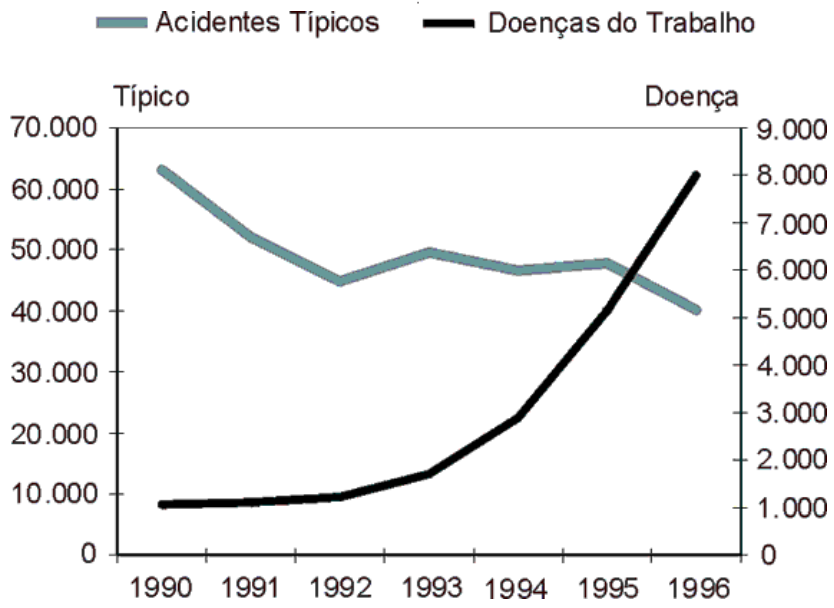

Fonte: INSS/Beat - Boletim Estatístico de Acidentes do Trabalhador, 1990-1996.

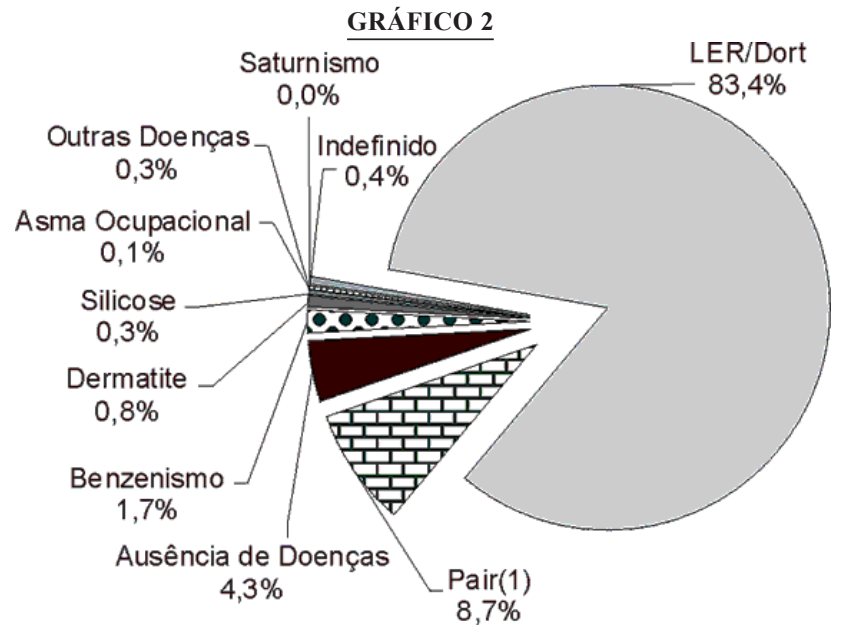

Fonte: Relatório do Nusat/INSS-MG - 1996.

(1) Perda auditiva induzida por ruido.

A ascensão dos casos de LER/Dort nos anos 90, além de facultar índices já caracterizados como epidêmicos, indica, sem dúvida, a sua maior proeminência entre todas as doenças ocupacionais atendidas pelo Nusat/INSS-MG. Aliás, essas doenças não foram apenas crescentes em diagnósticos, como também se tornaram campeãs absolutas na distribuição dos benefícios acidentários por espécie diagnosticada. ${ }^{14}$

Em adição ao Gráfico 2, vale registrar que, ainda em 1996, a maior incidência das LER/Dort no rol das doenças ocupacionais confirma que estão em primeiro lugar tanto nos atendimentos individuais $(49,2 \%)$ como nos atendimentos coletivos $(92,3 \%)$ do Nusat. Sintomaticamente, mesmo nos atendimentos por ausência de doença profissional, as suspeitas de LER foram as mais expressivas $(32,6 \%)$, seguidas, de longe e em ordem decrescente, pelas suspeitas de leucopenia $(22,1 \%)$, perdas auditivas induzidas por ruído - Pair (18,6\%), asma/alergia respiratória $(5,8 \%)$, etc.

Considerando-se todo o período 1991-96 (Tabela 2), o incremento das LER/Dort na RMBH, estimado pela taxa geométrica de crescimento, ocorreu a uma taxa média de $32,8 \%$ ao ano. Valor que, além de preocupante como questão de saúde pública, foi muito superior a qualquer outro indicador sociodemográfico apresentado anteriormente.

\section{CARACTERIZAÇÃO E ANÁLISE DAS LER/DORT}

Veremos que as manifestações das LER/Dort, atendo-se aos mecanismos de exclusão social, se dão por diferencia- 
TABELA 1

Distribuição das Pessoas com LER/Dort Atendidas pelo Nusat, segundo Faixa Etária Região Metropolitana de Belo Horizonte - 1992-98

\begin{tabular}{lrrrrrrr}
\hline \multirow{2}{*}{ Faixa Etária } & \multicolumn{5}{c}{ Pessoas com LER/Dort Atendidas pelo Nusat } \\
\cline { 2 - 7 } & 1992 & 1993 & 1994 & 1995 & 1996 & 1997 & 1998 \\
\hline Total (Nos Absolutos) & 328 & 550 & 554 & 1.160 & 1.703 & 1.373 & 815 \\
Total (\%) & 100,0 & 100,0 & 100,0 & 100,0 & 100,0 & 100,0 & 100,0 \\
Até 20 Anos & 1,2 & 1,5 & - & 0,7 & 1,8 & 0,8 & 1,5 \\
20 a 29 Anos & 42,4 & 42,2 & 30,9 & 36,8 & 34,1 & 29,6 & 23,9 \\
30 a 39 Anos & 36,3 & 37,1 & 43,5 & 37,0 & 37,2 & 39,5 & 36,0 \\
40 a 49 Anos & 17,1 & 16,5 & 21,8 & 21,7 & 21,8 & 25,3 & 31,4 \\
50 ou Mais & 3,0 & 2,7 & 2,9 & 3,7 & 5,2 & 4,7 & 7,1 \\
Não-Declarado & - & - & 0,9 & 0,1 & 0,0 & 0,0 & 0,1 \\
\hline
\end{tabular}

Fonte: Relatório do Nusat/INSS-MG - 1992-1998.

TABELA 2

ções marcantes tanto em suas características sociodemográficas - sexo, idade, escolaridade e renda - quanto em sua relação com os diferentes ramos de atividade econômica e a função desempenhada pelo lesionado na estrutura ocupacional, sendo esta última decisiva na compreensão das formas de desgaste e adoecimento do trabalhador.

Esta parte do artigo reporta-se parcialmente a trabalhos anteriores do autor, em que também foram utilizados dados do Nusat. Dados que resultaram de consultas exaustivas em seus arquivos e relatórios disponibilizados. Parte desse material, em forma de pôster, foi apresentada no VI Congresso da Abrasco (Salim, 2000a). Outra parte, de forma mais estruturada, foi utilizada em outro trabalho (Salim, 2001), do qual reproduzimos as tabelas 1, 4 e 5, na íntegra. No entanto, os demais quadros e tabelas foram remodelados e organizados conforme o escopo deste trabalho, ${ }^{15} \mathrm{o}$ qual redireciona a análise para as novas dimensões das LER/Dort, no que diz respeito ao seu caráter de exclusão social, decorrente tanto da segregação ocupacional como das relações de gênero que lhe são peculiares.

\section{Perfil Sociodemográfico}

Uma análise da estrutura etária dos trabalhadores portadores de LER/Dort indica uma clara predominância de casos na faixa etária de 30 a 39 anos, cujas taxas, refletindo participações extremas em dois momentos, oscilaram de 43,5\%, em 1994, para 36,0\%, em 1998. Tendo como referencial o intervalo de 20 a 39 anos, os percentuais naqueles anos foram $74,4 \%$ e $59,9 \%$, respectivamente. Apesar do relativo envelhecimento dos lesionados no tempo, até 1997 as frequiências relativas dos diagnósticos de trabalhadores Distribuição das Pessoas com LER/Dort Atendidas pelo Nusat, por Sexo
Região Metropolitana de Belo Horizonte - 1991-98

\begin{tabular}{|c|c|c|c|c|c|}
\hline \multirow{3}{*}{ Anos } & \multicolumn{5}{|c|}{ Pessoas com LER/Dort Atendidas pelo Nusat } \\
\hline & \multicolumn{2}{|c|}{ Mulheres } & \multicolumn{2}{|c|}{ Homens } & \multirow{2}{*}{ Total } \\
\hline & №s Absolutos & $\%$ & №s Absolutos & $\%$ & \\
\hline 1991 & 249 & 75,5 & 81 & 24,5 & 330 \\
\hline 1992 & 237 & 75,7 & 76 & 24,3 & 313 \\
\hline 1993 & 384 & 69,8 & 166 & 30,2 & 550 \\
\hline 1994 & 400 & 72,2 & 154 & 27,8 & 554 \\
\hline 1995 & 830 & 71,6 & 330 & 28,4 & 1.160 \\
\hline 1996 & 1.295 & 76,0 & 408 & 24,0 & 1.703 \\
\hline 1997 & 1.086 & 79,1 & 287 & 20,9 & 1.373 \\
\hline 1998 & 652 & 80,0 & 163 & 20,0 & 815 \\
\hline
\end{tabular}

Fonte: Relatório do Nusat/INSS-MG - 1991-1998.

vitimados, com idades entre 20 e 39 anos, não foi inferior a dois terços dos casos registrados. Por outro lado, considerando-se toda a série estatística (Tabela 1), observou-se que, apenas em 1994, não ocorreu qualquer registro de portador de LER/Dort entre trabalhadores com menos de 20 anos de idade - situação, infelizmente, não verificada nos demais anos, quando então, mesmo de forma oscilante, constataram-se registros de casos. ${ }^{16}$

Quanto à distribuição dos casos por sexo, por ora destacamos que, nos anos 90, as LER/Dort atingiram sobremaneira e de forma ascendente a mulher trabalhadora na RMBH.

Se no período 1991-96 responderam, em média, por quase três quartos dos casos diagnosticados, essa relação de tendência aumentou no tempo, passando de 76,0\%, em 1996, para 80,0\%, em 1998 (Tabela 2). 
Mesmo disponível apenas após 1994, a série histórica de dados sobre os níveis de escolaridade do portador de LER/Dort apresenta uma importante inversão de tendência. Como tal pode ser considerada como um dos sintomas de aprofundamento da exclusão social.

De fato, constata-se o seguinte: enquanto caiu a incidência de trabalhadores lesionados de nível superior passando de 22,4\%, em 1994, para apenas 9,6\%, em 1998 -, aumentou o registro daqueles cuja escolaridade não ultrapassava o primeiro grau, ou seja, com menos de oito anos de estudos: de 1994 a 1998 , passou de $30,1 \%$ para $45,7 \%$ (Tabela 3). Índices que corroboram a relevância do nível de escolaridade como elemento de peso na eficácia das ações preventivas voltadas à minimização dos danos de saúde no ambiente de trabalho.

De forma similar à escolaridade, a medição da variável salário por faixas de salários mínimos para a caracterização dos lesionados - que também passou a ser computada apenas a partir de 1994 - aponta, ao longo do tempo, para a tendência de maior incidência da doença entre os situados na base da pirâmide social - fato que reforça o seu caráter socialmente excludente.

$\mathrm{Na}$ realidade, o crescimento relativo dos portadores de LER/Dort com rendimento mensal situado entre um e dois salários mínimos elevou-se de 11,9\%, em 1994, para $29,8 \%$, em 1998. Considerando a faixa de lesionados que recebem até três salários mínimos, os índices foram 32,5\% e $45,2 \%$, respectivamente. Ainda no mesmo período, as maiores quedas observadas foram na faixa intermediária de três a cinco salários - de $23,7 \%$ para $18,2 \%$ - e na faixa dos que recebiam mais de cinco salários - de $38,1 \%$ para $27,0 \%$. Todavia, em relação à penúltima faixa, o ponto de inflexão, no sentido de descenso da curva, ocorreu a partir de 1995, quando, segundo os dados do Nusat, as LER/Dort passaram a ser mais diretamente associadas aos trabalhadores de menor renda (Gráfico 3).

\section{Segundo Ramos de Atividade Econômica e Ocupações}

$\mathrm{Na}$ caracterização das LER/Dort segundo ramos de atividade e ocupações, constatou-se, de longe, uma maior participação do setor Serviços no cômputo geral dos casos diagnosticados. Situação, no entanto, que não se resume apenas aos casos de doenças de trabalho, posto que outras modalidades de acidentes do trabalho - típico e de trajeto - também têm se estendido àquele setor. Como vimos, isso estaria relacionado a processos aparentemente díspares, porém não-divergentes, como a reorganiza-
TABELA 3

Distribuição das Pessoas com LER/Dort Atendidas pelo Nusat, segundo Escolaridade

Região Metropolitana de Belo Horizonte - 1994-98

\begin{tabular}{lrrrrr}
\hline \multirow{2}{*}{ Escolaridade } & \multicolumn{5}{c}{ Pessoas com LER/Dort Atendidas pelo Nusat } \\
\cline { 2 - 6 } & 1994 & 1995 & 1996 & 1997 & 1998 \\
\hline Total (№s Absolutos) & 554 & 1.160 & 1.703 & 1.373 & 815 \\
Total (\%) & 100,0 & 100,0 & 100,0 & 100,0 & 100,0 \\
Não-Alfabetizado & 0,7 & 0,9 & 1,1 & 0,7 & 2,0 \\
1o Grau & 29,4 & 41,6 & 46,2 & 40,4 & 43,7 \\
2o Grau & 45,5 & 39,7 & 40,2 & 41,2 & 43,9 \\
Superior & 22,4 & 15,0 & 12,2 & 13,9 & 9,6 \\
Técnico & 0,7 & 1,6 & 0,0 & 0,0 & 0,0 \\
Não-Declarado & 1,3 & 1,4 & 0,5 & 3,8 & 0,9 \\
\hline
\end{tabular}

Fonte: Relatório do Nusat/INSS-MG - 1994-1998.

\section{GRÁFICO 3}

Distribuição dos Atendimentos de LER/Dort, por Faixa de Salários Mínimos (SM) Região Metropolitana de Belo Horizonte - 1994-98

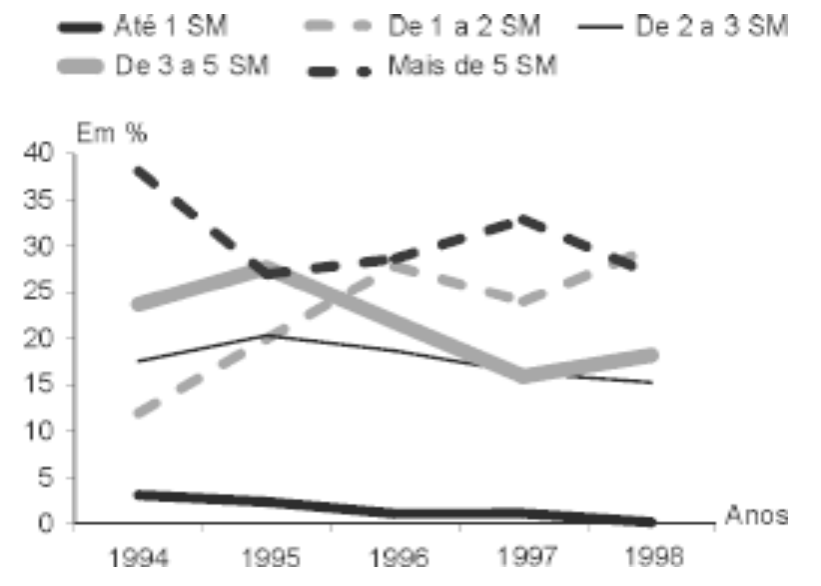

Fonte: Relatório do Nusat/INSS-MG - 1994-1998.

ção do trabalho, o avanço da precarização e os impactos das novas tecnologias.

Conforme Tabela 4, ao final do período localizado, apenas os ramos compostos pelas instituições financeiras, comércio varejista e prestação de serviços voltados às empresas que, sozinhos, responderam por $39,4 \%$ dos casos de LER/Dort na RMBH. Vale lembrar que no último ramo estão as atividades de terceirização, como, por exemplo, os serviços de vigilância, segurança e limpeza.

Em um período de seis anos, compreendido entre 1992 e 1998, as instituições financeiras reiteradamente continuaram campeãs na produção das LER/Dort. ${ }^{17}$ Também 
foi considerável o aumento na participação do comércio varejista - supermercados e lojas de artigos variados que, desde 1996, aproxima do índice das instituições financeiras. Em 1998, enquanto essas intituições responderam por $13,9 \%$ dos diagnósticos de LER/Dort, o comércio varejista, que também passou pela modernização tecnológica, respondeu por 12,6\%, ocupando, ainda, o segundo e terceiro lugares nos anos de 1996 e 1997, respectivamente $13,0 \%$ e $12,7 \%$.

Por fim, dois outros ramos de atividade devem ser destacados: serviços de saúde e prestação de serviços. O primeiro, ironicamente por pertencer ao setor saúde, mas também porque sofreu impactos da sua reestruturação produtiva como terceirização e o uso intensivo de novas tecnologias (Pires, 1998) -, elevou sua participação na incidência das LER/Dort de 4,7\%, em 1993, para 11,5\%, 1998, passando do oitavo para o quarto lugar no período. ${ }^{18} \mathrm{O}$ segundo, atrelado ao processo de terceirização e expandindo-se velozmente no período, destacou-se sobretudo no ano de 1998, quando, com $12,9 \%$ dos casos, representou o segundo ramo com o maior número de trabalhadores acometidos por LER/ Dort na RMBH. Comparativamente, seu valor foi de $8,1 \%$ em 1997 (Tabela 4). ${ }^{19}$

Consoante tal situação, foram constatadas mudanças expressivas no perfil das ocupações dos trabalhadores portadores de LER/Dort atendidos e diagnosticados no Nusat.

Inicialmente, o maior número de diagnósticos dessas doenças concentrou-se na categoria dos digitadores, que ocupou o primeiro lugar em todo o período 1991-1994. $\mathrm{Na}$ época, o segundo e terceiro lugares foram os seguintes: telefonista e auxiliar de produção na indústria eletrônica, em 1991; auxiliar administrativo e telefonista, em 1992; auxiliar de escritório com digitação e caixa bancário, em 1993; caixa bancário e auxiliar de escritório, em $1994 .^{20}$

Na segunda metade dos anos 90, os digitadores perderam a posição de liderança anterior. Situação explicada pelas evidências de diferenciações nas condições de trabalho por categoria, basicamente decorrentes de ações preventivas tópicas ou, o mais provável, pela maior mobilidade do trabalho, possibilitada, por exemplo, pela rotatividade da mão-de-obra. De qualquer forma, outras ocupações tornaram-se ou permaneceram relevantes nas manifestações das LER/Dort, como trabalhadores dos serviços de saúde, caixas comerciários, faxineiras e trabalhadores dos serviços de limpeza, caixas bancários e escriturários (Tabela 5).

\section{Sobre o Desgaste da Força de Trabalho}

Como destacamos anteriormente, a exposição direta aos riscos em diferentes ambientes de trabalho determinaria, segundo a categoria das ocupações, escalas variadas no desgaste físico do trabalhador. Situação que, diante da qualidade e natureza dos dados acessados, aqui será analisada apenas da perspectiva da distribuição dos casos

TABELA 4

Distribuição das Pessoas com LER/Dort Atendidas pelo Nusat, segundo Ramo de Atividade Econômica (1) Região Metropolitana de Belo Horizonte - 1992-98

\begin{tabular}{|c|c|c|c|c|c|c|c|}
\hline \multirow{2}{*}{ Ramos } & \multicolumn{7}{|c|}{ Pessoas com LER/Dort Atendidas pelo Nusat } \\
\hline & 1992 & 1993 & 1994 & 1995 & 1996 & 1997 & 1998 \\
\hline Total (№s Absolutos) & 328 & 550 & 554 & 1.160 & 1.703 & 1.373 & 815 \\
\hline Total (\%) & 100,0 & 100,0 & 100,0 & 100,0 & 100,0 & 100,0 & 100,0 \\
\hline Instituições Financeiras & 23,8 & 26,7 & 35,4 & 20,5 & 16,7 & 21,0 & 13,9 \\
\hline Serviços de Comunicação & 10,7 & - & 6,5 & - & - & - & - \\
\hline Indústria Siderúrgica e Metalúrgica & 6,1 & - & - & - & - & - & - \\
\hline Indústria de Material Elétrico e Eletrônico & - & 10,5 & - & 9,2 & - & - & - \\
\hline Serviços de Saúde & - & - & - & 11,9 & 10,2 & 10,8 & - \\
\hline Comércio Varejista & - & 8,0 & - & - & 13,0 & 12,7 & 12,6 \\
\hline Serviço Administrativo de Locação de Bens Móveis & - & - & 10,3 & - & - & - & - \\
\hline Prestação de Serviços & - & - & - & - & - & - & 12,9 \\
\hline Outros & 59,5 & 54,7 & 47,8 & 58,4 & 60,0 & 55,6 & 60,6 \\
\hline
\end{tabular}

Fonte: Relatório do Nusat/INSS-MG - 1992-1998.

(1) Para cada ano, estão relacionados somente os três ramos que apresentaram o maior número de casos de LER/Dort. Daí o superdimensionamento de "Outros". 
TABELA 5

Distribuição das Pessoas com LER/Dort Atendidas pelo Nusat, segundo Ocupação (1) Região Metropolitana de Belo Horizonte - 1995-98

\begin{tabular}{|c|c|c|c|c|c|c|c|c|}
\hline \multirow{3}{*}{ Ocupação } & \multicolumn{8}{|c|}{ Pessoas com LER/Dort Atendidas pelo Nusat } \\
\hline & \multicolumn{2}{|c|}{1995} & \multicolumn{2}{|c|}{1996} & \multicolumn{2}{|c|}{1997} & \multicolumn{2}{|c|}{1998} \\
\hline & №s Absolutos & $\%$ & №sAbsolutos & $\%$ & №sAbsolutos & $\%$ & №sAbsolutos & $\%$ \\
\hline Total & 1.160 & 100,0 & 1.703 & 100,0 & 1.373 & 100,0 & 815 & 100,0 \\
\hline Auxiliar Administrativo/Auxiliar de Escritório & 119 & 10,3 & 201 & 11,8 & 143 & 10,4 & 87 & 10,7 \\
\hline Digitador & - & - & 155 & 9,1 & - & - & 47 & 5,8 \\
\hline Caixa Bancário & 112 & 9,7 & 149 & 8,7 & 124 & 9,0 & 70 & 8,6 \\
\hline Faxineira/Auxiliar & - & - & 129 & 7,6 & 154 & 11,2 & 98 & 12,0 \\
\hline Caixa Comércio & - & - & 104 & 6,1 & 97 & 7,1 & 69 & 8,5 \\
\hline Escriturário & - & - & - & - & 82 & 6,0 & - & - \\
\hline Trabalhador de Serviço de Saúde & 95 & 8,2 & - & - & - & - & - & - \\
\hline Montador de Chicote & 82 & 7,1 & - & - & - & - & - & - \\
\hline Trabalhador Industrial de Material de Transporte & 74 & 6,4 & - & - & - & - & - & - \\
\hline Outros & 678 & 58,4 & 965 & 56,7 & 773 & 56,3 & 444 & 54,5 \\
\hline
\end{tabular}

Fonte: Relatório do Nusat/INSS-MG - 1995-1998.

(1) Para cada ano, estão relacionadas apenas as cinco ocupações que apresentaram o maior número de casos de LER/Dort.

TABELA 6

Distribuição das Pessoas com LER/Dort Atendidas pelo Nusat, segundo Tempo de Função Região Metropolitana de Belo Horizonte - 1994-98

\begin{tabular}{lrrrrr}
\hline \multirow{2}{*}{ Tempo de Função } & \multicolumn{5}{c}{ Pessoas com LER/Dort Atendidas pelo Nusat } \\
\cline { 2 - 6 } & 1994 & 1995 & 1996 & 1997 & 1998 \\
\hline Total (Nos Absolutos) & $\mathbf{5 5 4}$ & $\mathbf{1 . 1 6 0}$ & $\mathbf{1 . 7 0 3}$ & $\mathbf{1 . 3 7 3}$ & $\mathbf{8 1 5}$ \\
Total (\%) & $(1)) 39,5$ & $(\mathbf{1}) \mathbf{3 9 , 2}$ & 100,0 & 100,0 & 100,0 \\
< 6 Meses & 1,1 & 1,4 & 2,1 & 1,9 & 1,3 \\
De 7 Meses a 2 Anos & 8,5 & 9,4 & 21,4 & 16,5 & 9,8 \\
De 2 a 4 Anos & 6,9 & 8,4 & 18,4 & 15,8 & 18,4 \\
De 4 a 9 Anos & 10,1 & 9,5 & 26,0 & 27,7 & 24,8 \\
De 9 a 14 Anos & 7,9 & 5,2 & 13,0 & 17,7 & 27,7 \\
> 14 Anos & 5,1 & 4,6 & 17,1 & 19,4 & 16,8 \\
Não-Declarado & 0,0 & 0,8 & 2,1 & 1,1 & 1,1 \\
\hline
\end{tabular}

Fonte: Relatório do Nusat/INSS-MG - 1994-1998.

(1) Os dados dos relatórios estão incompletos para os anos assinalados.

Nota: Para 1994, o valor 39,5\% corresponde a um total de 219 casos, assim distribuídos: 92 digitadores, 91 caixas bancários, 23 montadores de chicotes e 13 operadores de produção na indústria automobilística; para 1995, o valor de 39,2\% corresponde a um total de 455 casos, assim distribuídos: 82 montadores de chicote, 112 caixas bancários, 119 auxiliares administrativos e de escritório, 68 digitadores e 74 trabalhadores na indústria de material de transporte.

diagnosticados por tempo de ocupação ou de exercício profissional em dada função.

No período focalizado, mesmo tendo diminuído os diagnósticos de LER/Dort entre os trabalhadores com pouco tempo na ocupação, observou-se, no geral, ainda uma elevada proporção desses trabalhadores portadores de LER/Dort, tendência que ocorreu - em graus e/ou ra-

\section{GRÁFICO 4}

Distribuição dos Atendimentos de LER/Dort, por Tempo de Função Região Metropolitana de Belo Horizonte - 1994-98

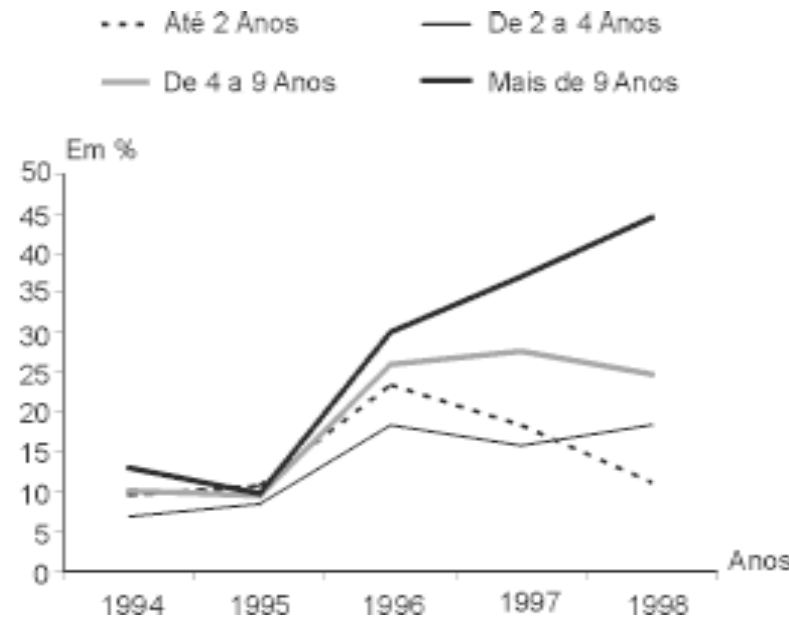

Fonte: Relatório do Nusat//NSS-MG - 1994-98.

mos de atividade variados - paralelamente à crescente rotatividade da mão-de-obra, informatização e automação de processos.

As ocorrências entre aqueles com até dois anos de trabalho, isto é, a partir de 1996, ainda permaneceram elevadas (Tabela 6): entre 1996 e 1998, os trabalhadores com tempo de trabalho segundo os estratos de 2 a 4 e de 4 a 9 
anos de atividade laboral (Gráfico 4) representaram, em média, respectivamente, cerca de $20 \%$ e $25 \%$ dos casos diagnosticados.

\section{LER/DORT E GÊNERO}

Na Tabela 2 constatamos que as LER/Dort acometeram majoritariamente a mulher trabalhadora da $\mathrm{RMBH}$, em curto espaço de tempo e de forma ascendente.

Sem dúvida, os números citados, mais do que meros suportes para indicadores quantitativos, em tese, revestem-se de riqueza de significado, constituindo-se em referencial ou ponto de partida para análises cujos desdobramentos teóricos poderiam ser amplos no plano interdisciplinar. Contudo, da perspectiva da análise formal, tais números não possibilitam uma adequada caracterização das LER/Dort no contexto das relações de gênero, pois seriam necessárias desagregações que não foram disponibilizadas pelo Nusat mas apenas os totais para ambos os sexos, em relação às seguintes variáveis: escolaridade, rendimento, ramo de atividade, ocupação e tempo na função dos lesionados.

Buscando superar essa lacuna, Wajnman et al. (1998) propõem, segundo sexo e grupos de base de ocupações da Rais, importantes questões sobre a hipótese de prevalência dessas doenças entre as mulheres - no caso, em parte, porque se referem apenas à distribuição dos casos de LER/Dort via dados do Nusat até 1996.

Desse modo, para o ano 1996, as autoras analisaram dois aspectos: o efeito de composição da sobredeterminação feminina nas ocupações mais prevalentes em LER/ Dort sobre a incidência diferencial por sexo $\mathrm{xo}^{21}$ e as tendências recentes de contratações de mulheres nas ocupações mais prevalentes.

No primeiro caso, mesmo que novas análises sejam necessárias, constatou-se a predominância feminina nos casos de LER/Dort. Segundo as autoras, "os casos femininos superam largamente os 50\%, exceto em cinco grupos: operadores de máquinas-ferramenta, classificadores de correspondências, carteiros e mensageiros, trabalhadores metalúrgicos e siderúrgicos não-classificados, reparadores de equipamentos elétricos e eletrônicos e pintores e decoradores de vidro e cerâmica". Sendo assim, hipoteticamente, por meio de estatísticas padronizadas, se os pesos dos sexos fossem similares, a proporção de mulheres com LER/Dort seria "sempre e muito acima dos 50\%, exceto apenas nos grupos de classificadores de correspondência, carteiros e mensageiros e trabalhadores meta- lúrgicos e siderúrgicos não-classificados, nos quais o peso relativo da participação feminina é ínfimo" (Wajnman et al., 1998:12).

Como o maior número de casos entre as mulheres não pode ser justificado em função da maior participação da força de trabalho feminina naquelas ocupações mais relacionadas a tais doenças, vale lembrar que dados agregados em níveis maiores podem, inclusive, mascarar as formas nas quais as relações de gênero se materializam numa mesma ocupação, em que, por exemplo, a mulher acaba assumindo tarefas mais monótonas e repetitivas, como observaram Cândido e Neves (1997). ${ }^{22}$

Como as LER/Dort não são outra coisa senão reflexo da impossibilidade de controle dos trabalhadores sobre a própria saúde, a expressão de sua desigualdade segundo o gênero revela seu lado trágico quanto à maior exposição e exploração da mulher como força de trabalho - situação, enfim, resultante do processo histórico de segregação ocupacional (Oliveira; Ariza, 1997), que, no geral, vem imputando à mulher um conjunto diferenciado de tarefas específicas, ou seja, mais repetitivas e monótonas.

Exatamente por isso, é essencial ir além da divisão do trabalho na busca de se compreender a desigualdade na distribuição das LER/Dort entre os trabalhadores, para situá-las no campo das relações de gênero, redefinidas, por sua vez, pelas novas formas de organização do trabalho, nas quais, sem dúvida, as condições de precarização têm-se revelado particularmente mais deletérias à saúde das mulheres.

Agravante é o fato que, no cômputo da distribuição da população assalariada na RMBH por sexo, a participação da mulher tem sido marcante nas empresas com até nove empregados, onde, não raramente, são mais problemáticas as ações preventivas de saúde e segurança. Nesse segmento de empresas, a participação relativa da força de trabalho feminina evoluiu de 35,6\%, em 1996, para 39,0\%, em 1998 (Fundação João Pinheiro/Dieese/Fundação Seade, 1999:3).

Considerando-se a distribuição da população desempregada na RMBH por sexo e idade, constata-se, em 1998, que, entre as mulheres desempregadas, as faixas etárias relativamente mais expressivas - isto é, de 18 a 24 anos, com 35,3\%, e de 25 a 39 anos, com 33,5\% - são praticamente coincidentes com aquelas em que as LER/Dort têm sido mais freqüentes. Aliás, a última faixa, a mais extensa, constitui a única em que o desemprego entre as mulheres é superior ao dos homens (Fundação João Pinheiro/ Dieese/Fundação Seade, 1999:4). Todavia, o perfil da po- 
pulação desempregada segundo o atributo sexo indica o seguinte: em 1998, de um contingente de 297 mil desempregados na RMBH, 51,1\% eram mulheres e 48,9\% homens. Mais especificamente, "enquanto a taxa de desemprego anual para ambos os sexos foi de 15,9\% da PEA, $18,7 \%$ das mulheres economicamente ativas encontravamse na situação de desemprego, contra 13,7\% dos homens" (Fundação João Pinheiro/Dieese/Fundação Seade, 1999:3).

Ademais, a par da discriminação, que acaba dificultando o acesso da mulher a determinadas ocupações - sobretudo no setor industrial, o mais formalizado e protegido - , as diferenças de rendimento entre homens e mulheres, mesmo com a elevação do nível de escolaridade das últimas, reforçam as desigualdades de gênero no mercado de trabalho. Desigualdade, indubitavelmente, que acabou refletindo no quadro geral e dinâmico das LER/Dort na $\mathrm{RMBH}$.

\section{CONCLUSÕES}

Como citado anteriormente já indicaram elementos relacionados à compreensão das determinações, dinâmica e principais impactos das LER/Dort, apontaremos, como conclusão, alguns aspectos mais gerais que, por serem de alcance maior, extrapolam, digamos, o próprio espaço da RMBH. Com isso, não estamos minimizando a necessidade de aprofundamento de alguns aspectos abordados, em especial quanto à análise mais detida de algumas variáveis ou, em nível mais global, à verificação do suposto "efeito de composição da sobredeterminação feminina" em certas ocupações e, mais especificamente, acerca das tendências e variações no tempo das contratações de mulheres naquelas ocupações mais prevalentes, como sugerem Wajnman et al. (1998).

Reflexo da "reestruturação produtiva" e principalmente das novas formas de organização do trabalho que lhe são afeitas, a epidemia de LER/Dort também se imbricaria às pressões inerentes à maior exploração da força de trabalho advinda tanto de novas tecnologias e situações de riscos como dos imperativos relacionados, por um lado, ao estreitamento do mercado formal de trabalho e, por outro, ao alargamento do setor informal, cujas precariedades reforçariam os agravos à saúde do trabalhador. No caso, o processo de terceirização, transferindo custos e reduzindo ainda mais as condições de trabalho, reforçaria esses agravos, pela possibilidade de maior rotatividade dos trabalhadores, burla à legislação trabalhista e omissão à atenção com a saúde do trabalhador.
Já as variações dos casos de LER/Dort em relação aos ramos de atividade econômica - expressivas, sem dúvida - não seriam senão reflexo das mudanças ocorridas no mercado de trabalho e, sobretudo, na organização dos processos de trabalho, tal como constatamos na RMBH, mormente em segmentos fabris e do setor Serviços que sofreram impactos mais diretos na informatização e automação. No geral, esses segmentos aprofundaram a subordinação do trabalho vivo ao trabalho morto, possibilitando um maior controle do trabalho em si, através de máquinas, atividades repetitivas, tarefas pouco diversificadas, etc. Sendo assim, o advento dos novos processos se relacionaria não apenas à maior sobrecarga de trabalho originária da redução de postos e número de pessoal empregado como também ao aviltamento das tarefas, à intensificação do ritmo do trabalho e assim por diante. Nesse sentido, a própria alternância das ocupações geradoras de LER/Dort nos anos 90, assim como as variações na exposição aos riscos em ambientes de trabalho, associadas ao desgaste decorrente do tempo no exercício da função pelo trabalhador/trabalhadora, dá conta da complexidade de suas determinações sociais. Isso sem considerar as intricadas questões relacionadas aos diagnósticos clínicos e à luta na busca por direitos dos lesionados; luta que, para muitos, é contraponto à ameaça maior do processo de exclusão social. Processo cujos impactos na RMBH têm estigmatizado sobretudo trabalhadores jovens, em sua maioria do sexo feminino, situados nos níveis mais baixos de escolaridade e renda.

Por fim, destacamos duas particularidades inerentes às LER/Dort que, de certa forma, são convergentes ou sobrepostas: a síndrome da exclusão e a questão da segregação por gênero.

A primeira, de forte impacto social, se explicaria pela qualidade de vida negada, uma vez que os incapacitados por essas doenças, majoritariamente jovens e mulheres, situando-se nas faixas etárias mais produtivas do ciclo de vida, vêem-se, pela invalidez ou aposentadoria precoce, sem o referencial de vida que a sociabilidade pelo trabalho, em tese, representaria para eles ante a impossibilidade da doença ocupacional.

A segunda, na perspectiva das relações de gênero, se expressaria pela proporção majoritária das mulheres entre os portadores de LER/Dort. Fato essencialmente resultante dos processos de divisão social e sexual do trabalho que, invariavelmente, têm respondido pela exclusão social e econômica das mulheres (Oliveira; Ariza, 1997). Vale dizer: pela determinação da segregação por gênero 
no mercado de trabalho, a partir de situações concretas, como, por exemplo, as condições precárias do trabalho feminino extradoméstico, agravadas pela segregação ocupacional e discriminação salarial das mulheres perante os homens. Em particular, a segregação ocupacional, ante a eventualidade da dupla jornada de trabalho - decorrente das divisões sexuais do trabalho na família e sociedade - ampliaria a possibilidade de desgaste da força de trabalho feminino e, por conseguinte, de mudança quanto à manifestação do gênero nas doenças do trabalho. Enfim, uma situação, como lembra Hirata (2001:111), na qual "os mais atingidos são os jovens, os pouco qualificados, do sexo feminino", ou seja, que não pode ser dissociada do quadro geral em que homens e mulheres vêm sendo distintamente afetados pelo desemprego devido a idade, qualificação profissional ou condição familiar.

Em resumo, neste trabalho, procuramos analisar um quadro no qual a manifestação das doenças do trabalho aqui também focalizadas da ótica da exclusão social - vem afetando, apesar de seus matizes, trabalhadores de ambos os sexos em diferentes estágios e circunstâncias de suas vidas produtivas. Infelizmente, como vimos, as estatísticas especializadas de que dispomos ainda não retratam as dimensões efetivas desse quadro senão como sorte de simulacro da realidade imediata.

\section{NOTAS}

1. A sigla LER (lesões por esforço repetitivo), tem o seu correlato em inglês que é RSI - Repetitive Strain Injuries. Recentemente, o governo alterou sua denominação para Dort - Distúrbios Osteomusculares Relacionados ao Trabalho (Diário Oficial da União, de 11 de julho de 1997). Como não há consenso sobre essa renomeação, e por concordarmos que tal procedimento, ao eliminar a idéia de repetitividade, retira a força do nexo causal da doença com o trabalho, optamos por manter a expressão original LER. Todavia, acatando sugestões ou procedimentos recorrentes, optamos aqui pela utilização da sigla geminada LER/Dort (Araújo, 2001).

2. Representativos, singulares e pontuais, esses dados viabilizaram grande parte da nossa análise empírica. Criado em 1989, como resposta ao crescimento das doenças ocupacionais, o Nusat foi, em âmbito nacional, órgão único do Instituto Nacional do Seguro Social - INSS. Localizado em Minas Gerais, suas ações, voltadas para o controle e prevenção das doenças ocupacionais, propiciaram a construção de importante banco de dados, que suportaram a publicação anual de estatísticas relativas à RMBH nos anos 90. Infelizmente, sob os influxos da "reestruturação" dos serviços públicos, o Nusat, que poderia ter servido de modelo para outras unidades da federação, foi, infelizmente, extinto ao final de 1999.

3. Estimativa apontada pelo economista Cláudio Dedecca, da Unicamp (Jornal do Brasil, 30/05/99).

4. Registre-se que, mesmo as Comissões de Conciliação Prévia-CCPs, criadas pela Lei Federal n ${ }^{\circ}$ 9.958, de 12/01/2000 -, com o objetivo de desafogar a Justiça do Trabalho e agilizar soluções para os conflitos, recentemente vêm sendo acusadas de práticas irregulares que lesariam os trabalhadores. Entre elas, a não-verificação da existência ou não de doença profissional nos acordos selados, ou seja, fecham acordos sem saber o resultado do exame médico demissional do trabalhador (Folha de S.Paulo, 07/09/2002, Caderno B, p.14).

5. Conforme AEPS - Anuário Estatístico da Previdência Social, 1999. Todavia, apesar de indicarem uma nova tendência, esses dados podem estar um pouco comprometidos pelo fato de empresas terceirizadas, muitas vezes vendedoras de serviços nos ramos industriais, serem, na verdade, meras prestadoras de serviços e, portanto, formalmente contabilizadas no setor Serviços. Daí a necessidade de novas pesquisas sobre o tema.

6. Ainda não há, entre os especialistas, consenso quanto à construção de coeficientes na área. Todavia, são reveladores alguns números divulgados, como, por exemplo, por Bombardi (2001:218), mostrando que os coeficientes de doenças profissionais no Brasil, para cada 100 mil trabalhadores registrados, elevaram de 26,92, em 1990, para 155,07, em 1998. O pico, ocorrido em 1997, foi de 196,37 casos.

7. $\mathrm{O}$ autor apresenta as marchas e contramarchas relacionadas às mudanças na legislação previdenciária acerca do diagnóstico das LER Dort. Especialmente, reporta-se à Norma Técnica de Avaliação de Incapacidade para Fins de Benefícios Previdenciários, publicada no Diário Oficial da União, em 20/08/98.

8. Essa pesquisa ouviu 1.072 trabalhadores com mais de 16 anos e de todos os ramos de atividade na cidade de São Paulo. Os entrevistados foram selecionados por sexo, idade, renda e escolaridade (Folha de S.Paulo, 07/10/2001, Caderno C).

9. No Rio de Janeiro, pesquisa do Sindicato dos Bancários entre os seus 32 mil associados revelou que praticamente $45 \%$ da categoria tinha sintomas da doença, ou seja, cerca de 14 mil trabalhadores (Jornal do Brasil, 25/03/01).

10. A ênfase no período 1991-96 não é arbitrária, uma vez que, orientada consoante as atualizações das principais fontes de dados do IBGE - Censo Demográfico, PNAD e PME -, possibilita análises comparativas mais acuradas, com base nos dados sociodemográficos e epidemiológicos disponíveis para período intercensitário. Também se refere ao período não apenas de plena atividade do Nusat como de ausência de menores barreiras institucionais quanto aos diagnósticos e reconhecimento das LER/Dort como doenças do trabalho. Ademais, o ano de 1996 correspondeu, na década de 90, ao momento de pico dos diagnósticos e atendimentos dos casos de LER/Dort.

11. A Pesquisa Mensal de Emprego (PME), do IBGE, privilegia a taxa de desemprego aberto em 7 dias. Metodologicamente diferente, a Pesquisa de Emprego e Desemprego (PED) da Fundação Seade e Dieese destaca, além da taxa de desemprego aberto em 30 dias, as taxas de desemprego oculto por trabalho precário e por desalento. Segundo essa, para 1996, a taxa de desemprego na RMBH oscilou de $11,8 \%$, em janeiro, para $10,7 \%$, em dezembro.

12. Cf. Araújo (2001). Ver nota 6 deste artigo. A propósito, registramos que, para todo o Estado de Minas, a partir dos dados do Anuário Estatístico da Previdência Social, foram estimados os seguintes coeficientes para cada grupo de 100 mil trabalhadores registrados: 180,63 , em 1995; 134,72, em 1996; 288,55, em 1997. Interessante é que, para 1997, o coeficiente de Minas foi muito superior ao do Brasil, de 196,37 casos. Veja coeficientes afins apresentados nas notas 6 e 16 deste trabalho.

13. Dados extraídos do Boletim Estatístico de Acidente do Trabalho do INSS e reproduzidos no Relatório Anual do Nusat de 1996 - dados que diferem daqueles publicados pelo Anuário Estatístico da Previdência Social, mas que, aqui, possibilitam uma análise comparativa das ocorrências entre municípios. Assim, considerando o período de 1995-1996, observou-se o seguinte crescimento relativo das doenças: $56,5 \%$, em Belo Horizonte; 54,2\%, em Contagem, -9,2\%, em Betim. Outros municípios mineiros, como Uberlândia e Juiz de Fora, dois importantes centros industriais, tiveram índices menores no período: 
o primeiro, com 548 casos em 1996, cresceu 30,8\%; o segundo, com 406 casos, teve um acréscimo de 19,7\%.

14. Durante 1996, a procedência da clientela do Nusat foi a seguinte: $65,6 \%$ de Belo Horizonte, 25,6\% da Grande Belo Horizonte e 8,8\% de outros municípios do Estado.

15. Aproveitamos para agradecer enfaticamente ao estagiário de estatística Antônio Padma Franco Vidal Mota por sua valiosa colaboração e apoio de última hora nessas tarefas.

16. Os números absolutos para cada ano, assim como suas participações relativas são: em 1992, 4 (1,2\%); em 1993, 8 (1,5\%); em 1995, 8 (0,7\%); em 1996, 30 (1,8\%); em 1997, 11 (0,8\%); em 1998, 12 (1,5\%).

17. Em Minas Gerais, o ramo de intermediação financeira foi o que apresentou, em 1995, o mais elevado coeficiente de invalidez permanente em decorrência de acidentes de trabalho: 163,13 por $100 \mathrm{mil}$ trabalhadores. Na seqüência, respectivamente em segundo e terceiro lugares, vieram os ramos da indústria extrativa, com 145,75, e da construção, com 86,46 (apud Carneiro, 1997:85).

18. Dados não mostrados na Tabela 4 devido ao critério adotado.

19. Dados não mostrados na Tabela 4 devido ao critério adotado.

20. Uma análise mais detalhada da relação LER/Dort e ocupações, abrangendo o período 1991-96, encontra-se em Carneiro (1997:88-93).

21. Aqui as autoras lançaram mão de "proporções de casos femininos padronizadas, que exprimem qual seria a proporção de casos femininos de LER caso a participação de homens e mulheres na ocupação fosse a mesma (50\%)" (Wajnman et al., 1998:12).

22. Este trabalho sugere a importância de novos estudos com vistas à testabilidade de outras hipóteses.

\section{REFERÊNCIAS BIBLIOGRÁFICAS}

ANTUNES, R. Os sentidos do trabalho: ensaio sobre a afirmação e negação do trabalho. São Paulo: Boitempo, 1999.

ARAÚJO, J.N.G. A LER/Dort e Seguro de Acidentes do Trabalho (SAT): questão de saúde ou de política. In: CARVALHO NETO, A.; SALIM, CA. (Orgs.). Novos desafios em saúde e segurança no trabalho. Belo Horizonte: IRT; Fundacentro; Segrac, 2001, p.125-147.

BOLETIM IRT/PUCMINAS. Caracterização do mercado de trabalho na RMBH no período 1996-2000. Informativo mensal, ano 0, n.12, 2001.

BOMBARDI, S.M.J. Planos de ação e planejamento institucional em segurança e saúde no trabalho - atuação da Fundacentro. In: CARVALHO NETO, A.; SALIM, C.A. (Orgs.). Novos desafios em saúde e segurança no trabalho. Belo Horizonte: IRT; Fundacentro; Segrac, 2001, p.207-219.

BRAVERMAN, H. Trabalho e capital monopolista: a degradação do trabalho no século XX. Rio de Janeiro: Zahar, 1977.

CÂNDIDO, V.G.; NEVES, M.A. Gênero, trabalho e saúde: um estudo de caso da LER numa empresa do setor metalúrgico. In: LIMA, M.E.A.; ARAÚJO, J.N.G.; LIMA, F.P.A. LER: dimensões ergonômicas e psicossociais. Belo Horizonte: Health, 1997, p.181-200.

CARNEIRO, C.M. Perfil social da LER. In: OLIVEIRA, C.R. Manual prático da LER. Belo Horizonte: Health, 1997, p.63-95.

FUNDAÇÃO JOÃO PINHEIRO; DIEESE; FUNDAÇÃO SEADE. “A mulher no mercado de trabalho da RMBH: resultados da pesquisa de emprego e desemprego". Informativo PED/RMBH, ano 4, n.1, 1999.

HIRATA, H. Salariado, precariedade, exclusão? Trabalho e relações sociais de sexo-gênero. Uma perspectiva internacional. In:
COLETA, M.C. (Org.). Demografia da exclusão social: temas e abordagens. Campinas: Ed. Unicamp, 2001, p.105-118.

IBGE. Indicadores Conjunturais: Pesquisa Mensal de Emprego. Rio de Janeiro, 1991 e 1996.

Pesquisa Mensal de Emprego. Média Anual dos Indicadores (Série Histórica Suplementar: 1990-1996). Rio de Janeiro, 1997.

LAURELL, A.C.; NORIEGA, M. Processo de produção e saúde: trabalho e desgaste operário. São Paulo: Hucitec, 1989.

LIMA, F.P.A. A organização da produção e a produção da LER. In: LIMA, M.E.A.; ARAÚJO, J.N.G.; LIMA, F.P.A. LER: dimensões ergonômicas e psicossociais. Belo Horizonte: Health, 1997, p.237-263.

MINISTÉRIO DA PREVIDÊNCIA E ASSISTÊNCIA SOCIAL. AEPS Anuário Estatístico da Previdência Social. Brasília: DIGI.N; Dataprev, 1999.

NUSAT. Relatório anual do Núcleo de Referência em Doenças Ocupacionais da Previdência Social. Belo Horizonte, 1991-1998.

OFFE, C. Capitalismo desorganizado: transformações contemporâneas do trabalho e da política. 2.ed. São Paulo: Brasiliense, 1989.

OLIVEIRA, O.; ARIZA, M. División sexual del trabajo y exclusión social. Revista Latino-americana de Estudos do Trabalho, ano 3, n.5, p.183-202, 1997.

PIRES, D. Reestruturação produtiva e trabalho em saúde no Brasil. São Paulo: Annablume, 1998.

POCHMANN, M. O trabalho sob fogo cruzado: exclusão, desemprego e precarização final do século. São Paulo: Contexto, 1999.

REVISTA PROTEÇÃO. Anuário Brasileiro de Proteção. Novo Hamburgo: MPF Publicações Ltda., 2001 (Edição Especial).

SALIM, C.A. A trajetória dos acidentes do trabalho e o crescimento das lesões por esforços repetitivos no setor de serviços e comércio da RMBH. In: CARVALHO NETO, A.; SALIM, C.A. (Orgs.). Novos desafios em saúde e segurança no trabalho. Belo Horizonte: IRT; Fundacentro; Segrac, 2001, p.79-98.

Trabalho, saúde e gênero: um estudo sobre as lesões por esforços repetitivos. In: CIÊNCIA E SAÚDE COLETIVA: VI CONGRESSO BRASILEIRO DE SAÚDE COLETIVA. Resumos... Salvador: Abrasco, v.5, Suplemento 2000, ago. 2000 a.

Estatísticas sobre doenças e acidentes do trabalho no Brasil: limites e possibilidades. In: SEMINÁRIO NACIONAL - ESTATÍSTICAS SOBRE DOENÇAS E ACIDENTES DO TRABALHO NO BRASIL: SITUAÇÃO E PERSPECTIVAS. Anais... São Paulo: Fundacentro, 2000b, p.83-88.

Informações sobre doenças e acidentes do trabalho no Brasil: uma avaliação crítica. In: XV CONGRESSO MUNDIAL SOBRE SEGURANÇA E SAÚDE NO TRABALHO. Sessão Gerenciamento da Segurança e Saúde no Trabalho. Resumos... São Paulo: MTE; OIT; AISS, 12-16 abr. 1999.

TOLEDO, E.G. La flexibilidad del trabajo en América Latina. Revista Latino-americana de Estudos do Trabalho, ano 3, n.5, p.129-57, 1997.

WAJNMAN, S. et al. As conseqüencias das lesões por esforço repetitivo (LER) sobre a atividade feminina. Belo Horizonte: Cedeplar; UFMG, 1998 (mimeografado).

WALDVOGEL, B.C. Acidentes do trabalho: os casos fatais - a questão da identificação e da mensuração. Belo Horizonte: Fundacentro; Segrac; Prodat, 2002. (Coleção de Estudos e Análises).

Celso Amorim Salim: Sociólogo, Coordenador do Programa de Melhoria das Estatísticas sobre Doenças e Acidentes do Trabalho Fundacentro, Minas Gerais (cas.cemg@terra.com.br). 